\title{
Blended Learning: A Case Study of Select Secondary Schools at Aligarh Muslim University, Aligarh, Uttar Pradesh
}

Sumbul Shahid

Research Scholar

Department of English

Aligarh Muslim University

Aligarh, Uttar Pradesh, India

Athar Afsar Sulaiman

Research Scholar

Department of English

Aligarh Muslim University

Aligarh, Uttar Pradesh, India

atharaas@gmail.com

\section{Abstract}

Online learning has been gaining wide publicity across the globe, helping people gain access to high quality courses in their field of study or work with highly qualified instructors available at a click.

People from non-native English countries have managed to improve manifold in language with the help of e-tutors in improving their English. While the world has been updating and educating itself with e- learning programmes, there still exist places where e- learning is still an alien concept. 
This paper will explore the need of blended learning to teach/learn English language at one of such places, Secondary Schools at Aligarh Muslim University. It will also shed light on the advantages and disadvantages of an effective blended learning. The authors aim to highlight the teaching methodologies used at this level. This study will use the questionnaire- based method with a two- point scale questionnaire, so that the respondents i.e. both teachers and learners at this level can easily answer in 'Yes' or 'No'.

Introduction

The first international survey on how blended and online learning was being implemented on primary and secondary students was conducted by the North American Council for Online Learning (NACOL) in 2006.

In the education race if major changes are observed, it is credited to the technological advancements. These changes have made learning and teaching process learner- centred. The current generation has been emerging in a globe where opportunity and information is only a touch away. The current day youth has been oozing with information and pursuit for novel knowledge. Now, the requirement is to synthesize and systematize the information so it can be corresponded with a suitable course. In the current world it has become a prerequisite to be up-to-date with knowledge and the latest trends. All these things are precursors of development. The current era has been bursting with technology and thus posing more challenges for the educators. Between knowledge and students, teachers are the most effective medium, so they need to be skilful and updated. Technological advancement has made it possible to alter the techniques of learning, teaching and presenting information to the current day students. The question of the hour is that, has the moment come to launch technology in our teaching? The response is yes, it is high time to bring about changes in our predictable teaching methods. The current generation of students has become too techno 
savvy, and thus can collect information through the internet and various other means. The issue arises when it is time to synchronize this information. This is where the teacher steps in and changes his role from that of an instructor to that of a facilitator. The teacher shows the way to the students how to combine text book information with online information. Thus, this blend of text books and online material proves advantageous for the student. Information technology offer prospects to dispense and disseminate sources of learning and research development more successfully. In the next few years e-learning and ICT based technologies are expected to develop manifold, accounting for around $30 \%$ of all educational necessities. Traditional learning is a teacher-centred teaching system. In most of the traditional learning setting, students learn from the instructor- led approach. Traditional learning is coupled with teacher in front and desks in front. There is one teacher and many students with generalized teaching and with little or no focus on individual performance. Since there exists individual differentiation, students prefer individualized settings. In other words, students require materials that can match their abilities. Thus, comes the need of technology in Indian classrooms. New methods of teaching and learning consist of innovative thinking and use of technology. This method is known as blended learning. In Blended learning any time a student learns at least in part at a supervised brick-and-mortar location away from home and at least in part through online delivery with some element of student control over time, place, path, and/or pace; often used synonymously with Hybrid Learning (Horn and Staker, 2011). Blended learning supports all the benefits of e-learning including cost reductions, time efficiency and location convenience for the learner as well as the essential one-on-one personal understanding and motivation that face to face instruction presents. (Brown, 2003; Yonge, 2014). Blended learning is a student centred method. Blended learning illustrates the learning environment as combination of teaching methods, media format, delivery methods and a fusion of all of these. On the basis of the above discussion, we can say that blended 
learning is a type of learning that mixes various event-based activities, including face-to-face classroom, live e-learning and self-paced instruction (Valiathan, 2006). It can also be said that blended learning is a combination of traditional learning and e- learning. It is a pioneering educational solution with a combination of online and traditional learning. A study by Dean and associates demonstrated that traditional learning in addition to numerous online options amplified students' learning. Blended learning will offer vast convenience for the learner to accomplish their objectives by combining the face to face communication in traditional learning and place, time and material abundance made available by Web-based learning. Y1lmaz \& Orhan (2010) state that the best way to solve the lack of interaction problem faced in technology-based learning is to blend traditional learning and online learning. Blended learning is a great method to bond present day learners with abundant knowledge. It has the potential to meet the current day requirements of globalization; it is an innovation in education to keep information and knowledge of the globe in a technological nutshell.

\section{Need of Research}

Blended Learning has been finding its way in many schools and mostly at all levels. At secondary levels of A.M.U., though traditional classroom teaching approach is working fine, but it tends to become monotonous and less engaging. With digital tools at their disposal, students show an increase in their efficiency and engagement in classroom activities. Every learner is different and so is their learning ability. Blended Learning helps students to learn at their own pace without much control and pressure. At secondary level, students have to study 6-7 subjects simultaneously. In such cases, Blended Learning seems like a rescue. For example, before reading the entire Gulliver's Travels, they can watch the movie online. So this would help them get a deeper understanding with greater enthusiasm. 
Many literature review reports show that there have been studies of online learning environment and their relationship to students' performance (Bawaneh, 2011; Shamsi S. Bawaneh, 2011 Becker; Ahmad et al. 2006, Dowling et al., 2003; Kubey et al., 2001). As, many researches (Ahmad et al. 2006, Viera Boumová 2008, Mitchell and Frorer 2010), proved that blended learning has a positive effect on academic achievement of students. Researchers observed that many institutions still follow traditional classroom teaching method at secondary school level.

Objective of Study

Keeping the present teaching scenario in mind, the best thing about Blended Learning is that it reduces isolation of students thus paving way for more opportunities of interaction among students and their peers.

In case of A.M.U., one problem that is faced by the teachers is the background of the students because there are some who belong to the rural areas and hence they do not have any background knowledge about computer and other technologies which affect their level of motivation in a negative manner, thus increasing the cognitive load on young minds. Plagiarism and credibility is a problem with Blended Learning.

\section{Methodology}

During this research two types of methodologies were followed, one being activity based and the other survey based. For the first method which was activity based, students were divided into two groups. The first group was taught by the traditional method of teaching and the second group used blended learning approach. An achievement test was designed to find out the results. The traditional approach group was taught Gulliver'sTravels through lecture method whereas the blended learning group was shown the movie online. To 
achieve the objective, pre- reading activities and post- reading activities were also carried out with both the groups. The second method was a quantitative one making use of two separate sets of questionnaires, one for the students and the other for the teachers.

Data Analysis

A survey was carried in two secondary schools namely A.M.U Girls School and S.T.S High School of Aligarh Muslim University during the academic session 2018- 19, among 270 students (150 female students and 120 male students) with an average age group between 13 to 16 years. The mother tongues of the students were mainly Hindi and Urdu, with most of the students belonging to rural background.

The survey also was conducted among 10 teachers from both the schools having minimum 10 years teaching experience.

The questions of the students' response sheet were as follows:

1. Do you have language labs in your school?

2. Are you able to access authentic materials online?

3. Are you satisfied with the way your teachers teach you English?

4. Do you find the blend of online and traditional learning interesting?

5. Is classroom teaching different from online resources?

6. Do you feel the blend of traditional and online learning should be made a part of your curriculum? 
Table No. 1: Analysis of Students' Response

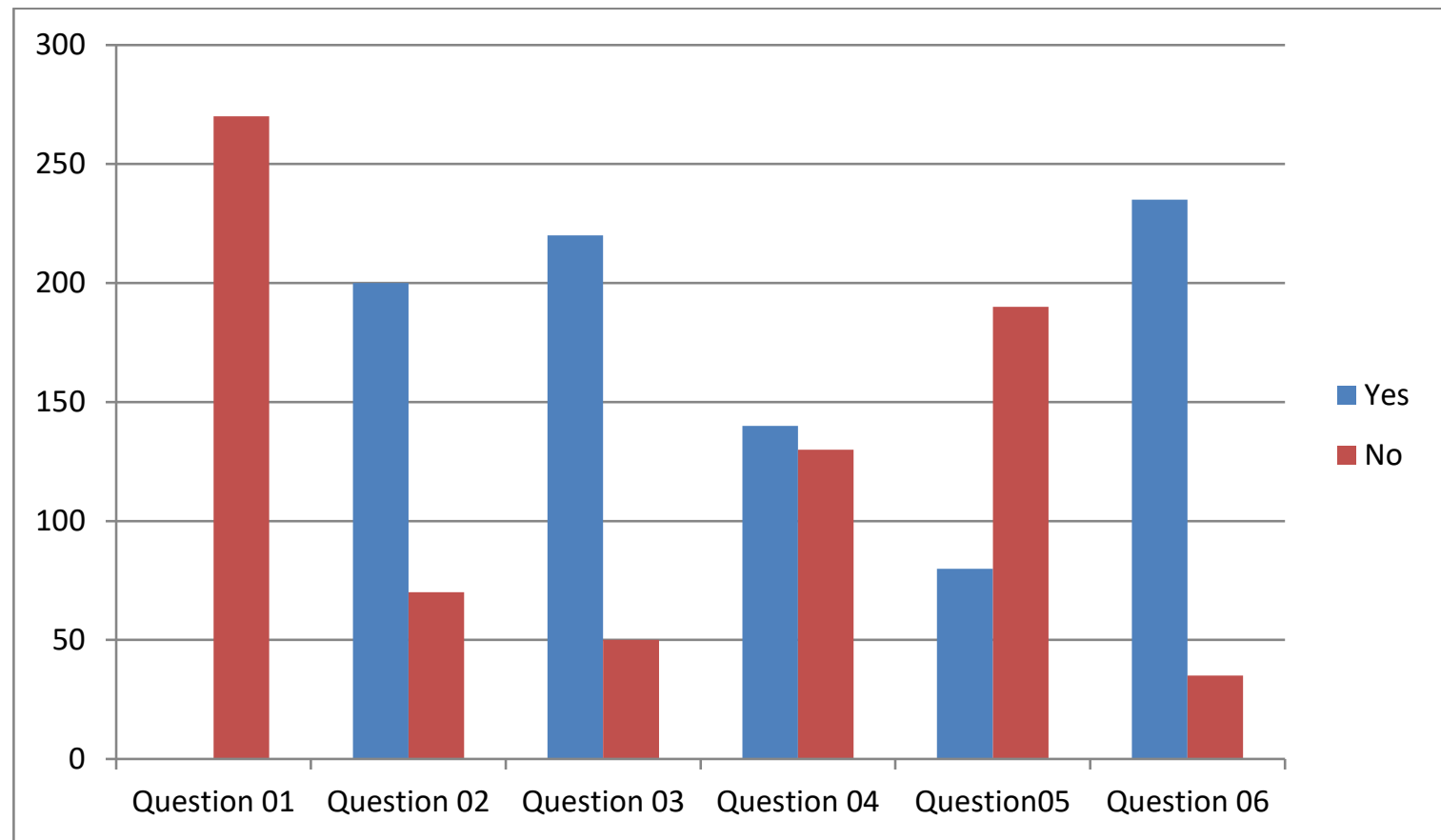

The survey conducted among the students gave the following results:

It was observed that there were no language labs in schools surveyed, as the answer to the first question was 'NO', which proved that a major source of blended learning was missing from the infrastructure.

The answer to the second question suggested that $74 \%$ of the students were able to access authentic material online whereas $26 \%$ were not able to do so. It was even observed that $81 \%$ students were satisfied with the way their teachers taught English. The response to the fourth question suggested that around 52\% students found the blend of online and traditional learning interesting whereas $48 \%$ students did not. In the answer to the fifth question, it was observed that only around $30 \%$ found classroom teaching different from online resources whereas $70 \%$ found both similar. Lastly, the response to the sixth question marked that $87 \%$ of the students wanted the blend of traditional and online learning be made a part of their curriculum whereas $13 \%$ students were satisfied with their present curriculum. 
The questions of the teachers' response sheet were as follows:

1. Do students respond well to online material?

2. Do you refer to online resources for teaching material?

3. Are the students motivated towards online learning?

4. Are the students able to absorb the blend between online and traditional learning?

5. Are you working to bridge the gap between traditional teaching methods and online resources?

6. Do you feel the blend of traditional and online learning should be made a part of your curriculum?

Table No. 2: Analysis of Teachers' Response

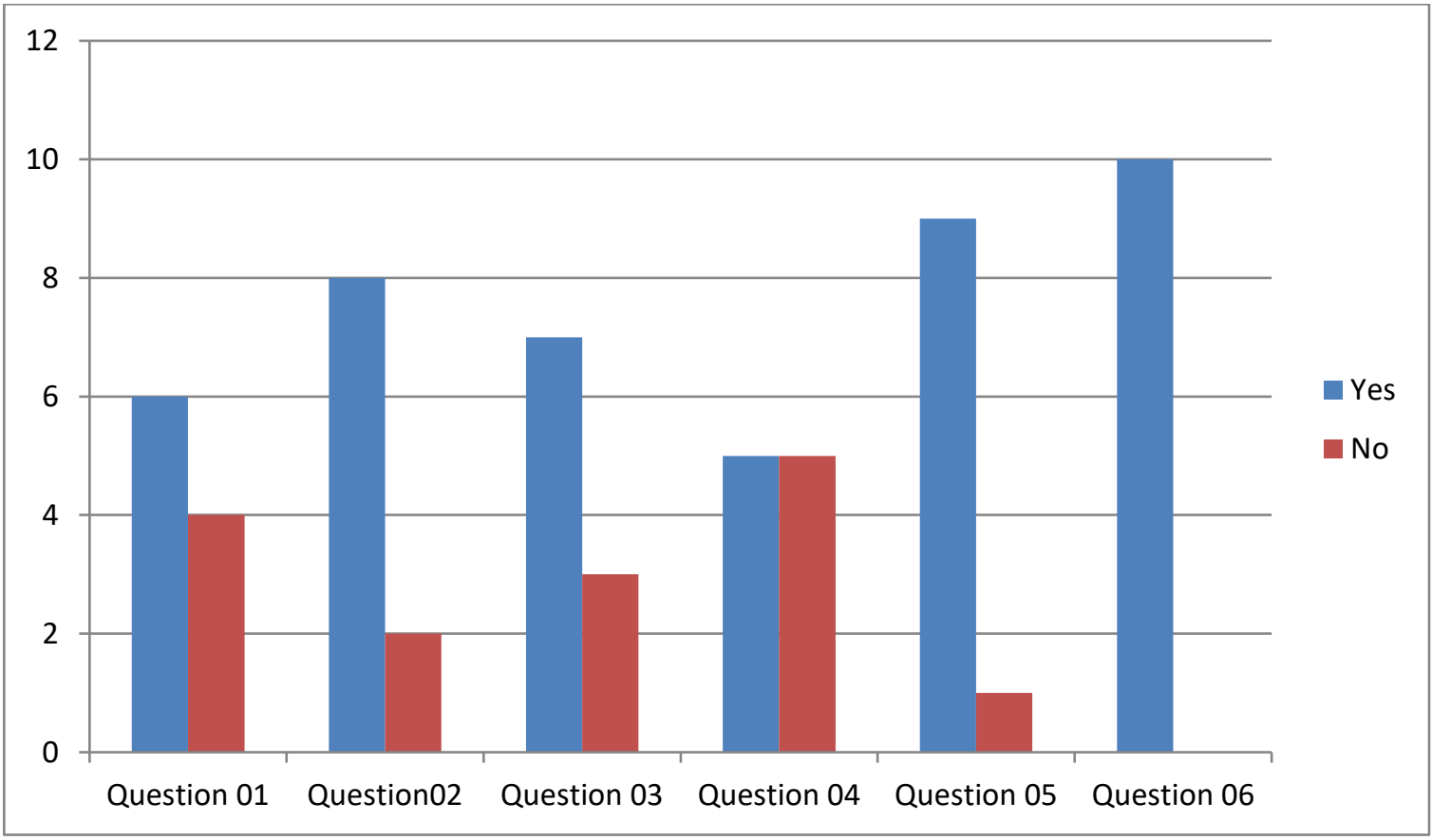

The survey conducted among the teachers gave the following results:

- To the first question $60 \%$ of the teachers found that the students responded well to online materials whereas $40 \%$ responded with a negative mark. 
- On the second question $80 \%$ of the teachers referred to online teaching material, and $20 \%$ did not find the need to refer online with the current curriculum.

- $70 \%$ teachers found the students motivated towards online learning, but $30 \%$ thought that online learning did not motivate the students at all.

- The response to the fourth question was a mixed one with $50 \%$ teachers believing that students are able to absorb the blend between online and traditional learning and 50\% were against this notion.

- It was observed that $90 \%$ of the teachers wanted to bridge the gap between traditional teaching methods and online resources, while $10 \%$ did not find it necessary.

- Lastly, $100 \%$ of the teachers were in favour of the notion that the blend between traditional and online resources should be made a part of the curriculum.

\section{Results and Findings}

The activity based research showed a significant difference between both the groups, thus proving that the blended learning approach gave better results. The students understood better and in less time. The blended learning approach was informal but gave more authentic results than the traditional method.

The survey based research hypothesized that blended learning can be used as an important aid to enhance the knowledge and comprehension of the students beyond the boundaries of the classroom, but it also has its own challenges, because most of the students belong to the rural background and first they need to be made aware of the plethora of knowledge available online.

It was also observed that blended learning was a technological challenge because adequate IT literacy and tech support were a major barrier and missing from the infrastructure of these institutions. 


\section{Recommendations}

Blended learning should be extensively used at secondary school level and can be very beneficial for adaptation and distribution of online educational material, which will promote its widespread availability. There is an urgent need to digitize education to make students technologically at par with rest of the world. 


\section{References}

Patrick, S. and Powell, A. "An International Perspective of K-12 Online Learning: A Summary of the 2006 NAOCL International E- Learning Survey." 2006. <http://www.inacol.org/research/docs/InternationalSurveyResultsSummaries.pdf>. iNACOL. Online Learning Definitions Project. Vienna: iNACOL, 2011.

Bawaneh SS. Does using computer technology improve students' performance? Evidence from a management. International Journal of applied Science and technology 2011.

Bawaneh S. Effects of Blended Learning Approach on Students' Performance: Evidence from a Computerized Accounting Course, International Journal of Humanities and Social Science, 2011, 1(6).

Dowling G, Godfrey J, Gyles N. Do hybrid flexible delivery teaching methods improve accounting students' learning outcomes? Accounting Education: an international journal, 2003, 12(4).

Kubey RW, Lavin MJ, Barrows JR. Internet use and collegiate academic performance decrements: early findings, Journal of Communication, 2001, 51(2).

Brown R. Blending Learning: Rich Experiences from a Rich Picture. Training and Development in Australia, 2003, 30(3)

Valiathan P. Designing a blended learning solution. Instructional Design Expert, NIIT.LTD, 2006.

Yilmaz, Orhan. Pre-Service English Teacher in Blended Learning Education in respect to their learning Approaches. TOJET: The Turkish Online Journal of Educational Technology, 2010, 9(1). 